\title{
Modifikasi Wattmeter untuk Panel Listrik Menjadi Kit Modul Praktikum Wattmeter
}

\author{
Supian Nor ${ }^{1}$, Sri Hari Ningrum ${ }^{2}$ \\ 1Jurusan Teknik Elektro, Politeknik Negeri Samarinda.spn nr@polnes.ac.id, \\ 2Jurusan Teknik Elektro, Politeknik Negeri Samarinda. sriharining@polnes.ac.id
}

Submisi: 17 September 2021; Penerimaan: 11 Januari 2022

\begin{abstract}
ABSTRAK
Dalam rangka mengembangkan penelitian tentang peralatan praktikum di Jurusan Teknik Elektro Politeknik Negeri Samarinda, saat ini juga dipandang perlu untuk mengembangkan alat ukur listrik yang berfungsi untuk memudahkan praktikum dan mengurangi resiko tersengat aliran arus listrik saat praktikum. Alat ukur listrik wattmeter yang umumnya dipasang dipanel listrik yang digunakan untuk praktikum tanpa kotak panel atau dudukan penyangga tentunya akan sangat berbahaya. Nah, agar alat tersebut dapat digunakan dengan aman maka perlu dibuatkan tempat/wadah berupa kotak. Alat ukur listrik yang bernama Kit Modul Praktikum wattmeter ini akan sangat bermanfaat untuk digunakan di laboratorium kualitas daya dan laboratorium mesin listrik, mengingat di laboratorium listrik alat ukur wattmeter sudah banyak yang rusak. Kit Modul praktikum wattmeter ini dapat dijadikan alternatif untuk mengukur besaran daya listrik dalam suatu rangkaian listrik.

Kit modul Praktikum ini didesain agar aman digunakan pada saat pratikum, dengan menggunakan bahan isolator untuk meminimalisir konsleting listrik dan bahaya kesetrum pada pengguna, selain itu juga akan lebih mudah digunakan sehingga bisa menghemat waktu perakitan rangkaian listrik sehingga pengambilan data praktikum yang dilakukan mahasiswa berjalan lancar.
\end{abstract}

Kata kunci : alat listrik; praktikum; Kit modul ; wattmeter

\section{PENDAHULUAN}

Laboratorium Listrik Jurusan Teknik Elektro adalah tempat mahasiswa melakukan kegiatan praktikum. Di laboratorium listrik ini banyak tersedia peralatan listrik seperti alat ukur listrik, mesin listrik dan lain-lain.

Sebagian besar peralatan yang ada dilaboratorium listrik ini sudah cukup lama usianya, sehingga ada beberapa diantara sudah rusak atau tidak berfungsi dengan baik lagi. Dari data peralatan wattmeter yang penulis kumpulkan, didapatkan data bahwa wattmeter yang ada dilaboratorium listrik Politeknik Negeri Samarinda telah digunakan sejak tahun 1988 berjumlah 16, akan tetapi hanya satu buah yang dapat digunakan sedangkan 15 buah wattmeter lainnya sudah rusak.
Untuk peralatan-peralatan tertentu sudah sangat jarang ada dipasaran, bahkan yang serupapun hampir-hampir tidak ada, sehingga sangat sulit untuk melakukan penggantian baru. Untuk itu diperlukan suatu alat yang bisa menjadi alternatif pengganti alat yang rusak. Salah satunya adalah wattmeter digital panel listrik seperti pada gambar 1 dibawah ini.

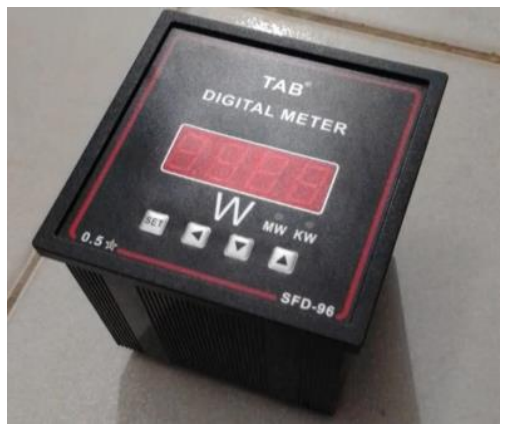

Gambar 1. Wattmeter Digital 3 phasa untuk panel listrik. 


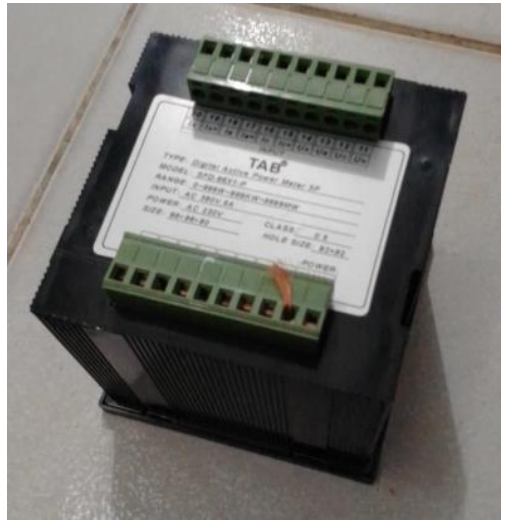

Gambar 2. Tampak belakangWattmeter Digital 3 phasa.

Peralatan wattmeter seperti pada gambar 1 dan gambar 2 diatas, dapat dijadikan alat alternatif pengganti wattmeter yang rusak, namun penggunaannya kurang aman dan kurang praktis, untuk itu perlu dilakukan modifikasi sehingga alat tersebut dapat digunakan dengan aman dan praktis. Dari permasalahan inilah kemudian penulis membuat penelitian dengan judul : "Modifikasi Wattmeter Panel Listrik Menjadi Kit modul Praktikum Wattmeter.

\section{METODOLOGI}

\section{Bahan Penelitian}

Bahan yang digunakan dalam penelitian ini antara lain adalah kabel NYAF, papan akrilik, timah solder, banana plug, resin, dan katalist.

\section{Alat Penelitian}

Proses rancang bangun prototype kit modul praktikum wattmeter yang dilakukan di Laboratorium Listrik Teknik Elektro akan menggunakan peralatanperalatan yang terdapat di Laboratorium. Beberapa alat yang akan digunakan selama dalam proses rancang bangun dan pengujian di antaranya adalah : Multimeter, Tang, Obeng, solder. Cutter Akrilik. Gurinda listrik, komputer, wattmeter 3 phasa.

\section{Pengujian kit modul praktikum}

Sebelum melakukan pengujian kit modul praktikum, system pengawatan di terminal-terminal kabel perlu dilakukan pengecekan terlebih dahulu dari kemungkinan terjadinya hubung singkat atau putus sambungan pada saat perakitan modul dengan menggunakan alat ukur ohm meter. Selanjutnya kit modul wattmeter diberikan sumber tegangan $220 \mathrm{~V}$, untuk memastikan wattmeter dapat beroperasi dengan baik.

Proses pengukuran, dengan menyalakan wattmeter, kemudian dilakukan pengaturan pada wattmeter. Selanjutnya kit modul praktikum wattmeter dihubungkan kebeban, menggunakan kabel penghubung. Setelah semua terhubung, listrik tegangan sumber yang kebeban dinyalakan, maka akan terlihat pada display wattmeter besaran daya yang mengalir kebeban.

\section{Analisis data}

Wattmeter yang akan dimodifikasi umumnya dipakai pada panel listrik. Tentunya jika ingin digunakan untuk praktikum diperlukan pula kotak panel listrik sebagai dudukannya. Kalau menggunakan kotak panel ini proses penyambungan/pelepasan kabelnya keterminal wattmeter akan lebih sulit dan membutuhkan waktu yang lama.

Sebagi pengganti kotak panel yang terbuat dari besi digunakan kotak berbahan isolator yaitu papan mika dengan menambahkan terminal soket pada permukaannya sehingga mudah untuk digunakan.

\section{HASIL}

Perbandingan pengaturan
instrument sebelum dan setelah
modifikasi disajikan pada Tabel 1. Hasil
pengukuran listrik yang dilakukan
disajikan pada Tabel 2.


Tabel 1. Perbandingan pengaturan instrument sebelum dan setelah modifikasi

\begin{tabular}{|c|c|c|}
\hline No. & Sebelum dimodifikasi & Setelah dimodifikasi \\
\hline 1. & $\begin{array}{l}\text { Mur sambungan terminal kabel terbuka, } \\
\text { membahayakan pengguna pada saat } \\
\text { digunakan, karena dapat tersentuh secara } \\
\text { tidak sengaja saat digunakan. }\end{array}$ & $\begin{array}{l}\text { Mur sambungan tertutup sehingga } \\
\text { alat aman untuk digunakan. }\end{array}$ \\
\hline 2. & $\begin{array}{l}\text { Dibutuhkan obeng untuk memasang dan } \\
\text { melepaskan kabel dari terminal kabel. }\end{array}$ & $\begin{array}{l}\text { Tidak dibutuhkan obeng untuk } \\
\text { menyambungkan kabel keterminal, } \\
\text { karena sudah digantikan dengan } \\
\text { menggunakan soket terminal, } \\
\text { sehingga jadi lebih praktis. }\end{array}$ \\
\hline 3 & $\begin{array}{l}\text { Mur Terminal sering mengalami keausan, } \\
\text { karena gesekan } \\
\text { dikencangkan/dilonggarkan. }\end{array}$ & $\begin{array}{l}\text { Soket yang digunakan kualitas } \\
\text { baik, tidak mudah rusak. }\end{array}$ \\
\hline 4 & $\begin{array}{l}\text { Pada percobaan, waktu yg dibutuhkan } \\
\text { untuk merakit rangkaian listrik lebih dari } 10 \\
\text { menit. }\end{array}$ & $\begin{array}{l}\text { Pada percobaan, waktu yg } \\
\text { dibutuhkan untuk merakit } \\
\text { rangkaian listrik kurang dari } 5 \text { menit }\end{array}$ \\
\hline
\end{tabular}

Tabel 2. Percobaan Pengukuran Daya Listrik.

\begin{tabular}{cccccc}
\hline No. & $\begin{array}{c}\text { Beban } \\
\text { (Watt) }\end{array}$ & $\begin{array}{c}\text { Tegangan } \\
\text { (Volt) }\end{array}$ & $\begin{array}{c}\text { Hasil } \\
\text { Pengukuran } \\
\text { (Watt) }\end{array}$ & $\begin{array}{c}\text { Sebelum } \\
\text { modifikasi } \\
\text { (Waktu 1) }\end{array}$ & $\begin{array}{c}\text { Surasi } \\
\text { modifikasi } \\
\text { (Waktu 2) }\end{array}$ \\
\hline 1 & $3 \times 100$ & 380 & 303 & $00: 15: 52$ & $00: 03: 06$ \\
2 & $1 \times 100$ & 220 & 100 & $00: 12: 21$ & $00: 00: 58$ \\
\hline
\end{tabular}

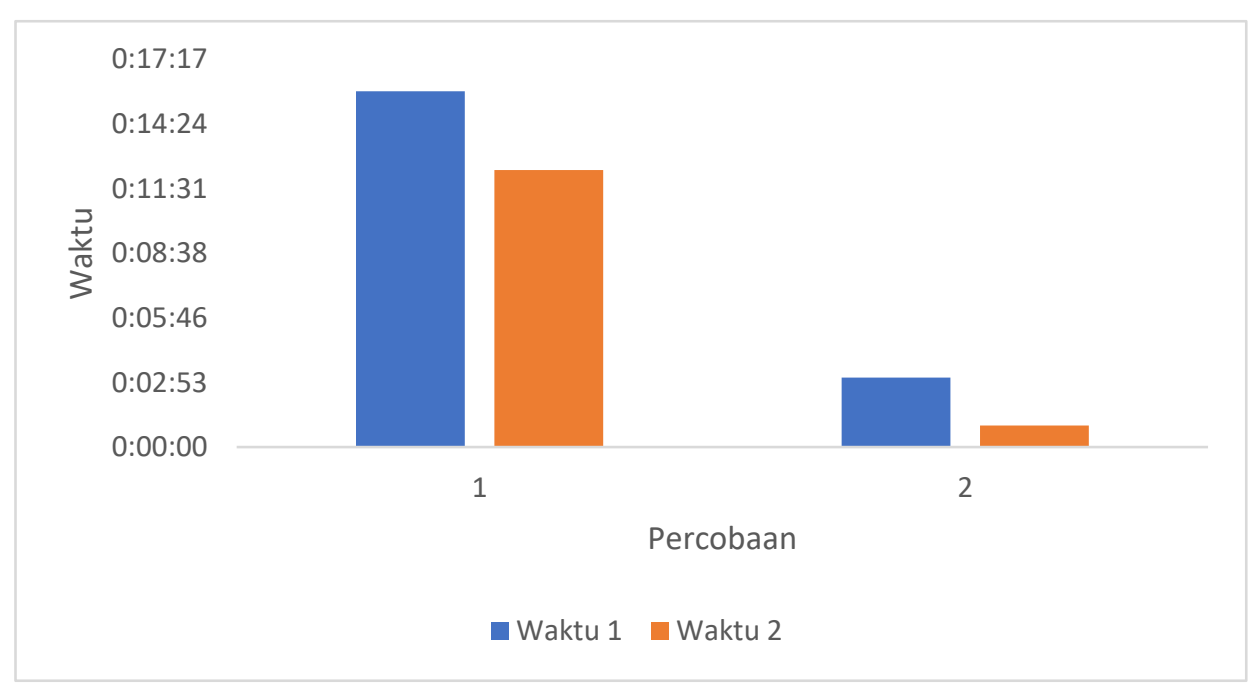

Gambar 3. Perbandingan waktu sebelum dan sesudah modifikasi

Berdasarkan Gambar 3 dapat diketahui bahwa waktu 1 lebih lama dari waktu 2, artinya waktu yang dibutuhkan untuk percobaan menggunakan alat yang telah dimodifikasi (waktu 2) lebih singkat dibandingkan waktu sebelum alat dimodifikasi.

\section{PEMBAHASAN}

Penelitian ini bertujuan untuk merancang bangun/memodifikasi wattmeter panel listrik menjadi Kit modul praktikum wattmeter yang akan digunakan di laboratorium listrik Jurusan 
Teknik Elektro Politeknik Negeri Samarinda. Kit Modul ini diberi nama Kit modul WATTMETER 3 phasa.

Sebagai langkah awal, tujuan penelitian ini adalah untuk merancang bangun konstruksi kit modul praktikum, yang bahan-bahan materialnya mudah didapat, dan dapat menunjang kegiatan praktikum dilaboratorium Listrik. Penulis kemudian melakukan pencarian bahan yang cocok untuk digunakan pada desain ini, maka dipilihlah bahan papan akrilik/mika. Kenapa bahan ini dipilih karena bahan ini bersifat isolator tidak menghantarkan arus listrik sehingga akan aman digunakan sebagai penutup rangkaian pengawatan wattmeter. Selain bersifat isolator, bahan ini juga

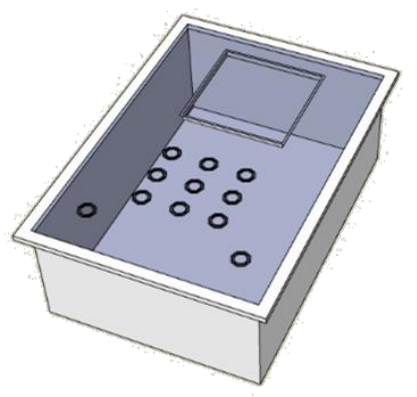

Gambar 3.Design Prototipe Kit modul Praktikum.

\section{Manfaat Penelitian}

Produk yang dihasilkan dalam penelitian ini sangat bermanfaat dan telah digunakan untuk kegiatan praktikum pada laboratorium Kualitas daya, Mesin Listrik, serta praktikum Sistem Distribusi Listrik, Jurusan Teknik Elektro Politeknik Negeri Samarinda, karena didalam praktikum tersebut ada pengukuran daya listrik 3 phasa.

Penulis berharap Prototipe yang diperoleh diproduksi di Politeknik Negeri Samarinda, sehingga dalam kurun waktu tertentu dapat digunakan untuk mudah diperoleh di pasaran dan mudah dibentuk menjadi sebuah papan modul. Proses pembuatan kit modul praktikum ini diawali dengan memotong papan akrilik/mika menjadi beberapa bagian sesuai dengan ukuran yang di inginkan. Kemudian buat gambar sketsa pada papan mika yang telah dipotong agar mudah dalam pengerjaan selanjutnya. Gunakan bor listrik untuk melubangi papan mika sesuai dengan sketsanya. Untuk bagian penutup belakang disini penulis menggunakan bahan resin sebagai perekat sekaligus sebagai pengikat baut untuk bagian penutup kit modul praktikum ini. Rancang bangun prototipe Kotak Kit Modul praktikum wattmeter diperlihatkan pada gambar 4 .

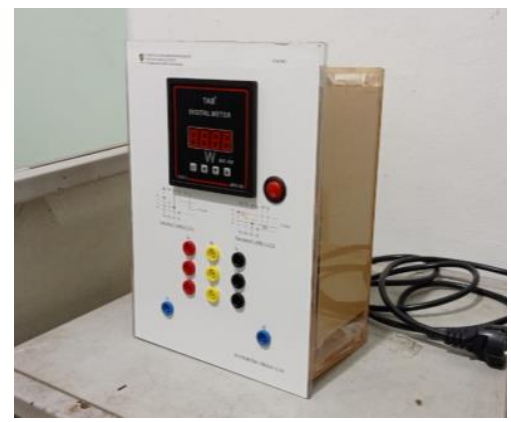

Gambar 4. Prototipe Kit modul Praktikum.

membantu melengkapi peralatan dilaboratorium listrik, industri, atau masyarakat yang membutuhkan. Selain itu, juga dapat digunakan sebagai motivasi bagi sivitas akademika Jurusan Teknik Elektro Politeknik Negeri Samarinda dalam membangun prototipeprototipe modul kit praktikum baru untuk peralatan lainnya.

\section{KESIMPULAN}

Dari hasil studi ini, dapat disimpulkan bahwa dengan modifikasi pada wattmeter ini maka dapat menjadi 
wattmeter pengganti yang aman digunakan karena pada bagian terminal yang dialiri listrik telah ditutup dengan kotak mika, selain itu pula efisiensi waktu percobaan bisa menjadi lebih cepat selesai dan dapat membantu membagi waktu praktikum mengikuti protokol kesehatan dimasa pandemi covid 19 seperti saat artikel ini dibuat.

\section{DAFTAR PUSTAKA}

Taufiqullah. 2021. Pengukuran Daya Tiga Fasa Dengan Wattmeter. https://www.tneutron.net/elektro/p engukuran-daya-tiga-fasa- dengan-wattmeter/ diakses pada Feb 22, 2021.

Aldian dan Andi Farid Hidayanto. 2019. Desain Papan Informasi Taman Samarendah Di Kota Samarinda. docplayer.info

Suyanto, M. 2004. Analisis dan Desain Aplikasi Multimedia untuk Pemasaran, Yogyakarta: PT. Andi Offset

Hermawan Udayunto Nugroho. 2014. Rancang bangun kit modul praktikum rangkaian listrik openlibrary.telkomuniversity.ac.id

Dr.Eng. Achfas Zacoeb, ST., MT ,(2016), Material Teknologi I Plastik dan Kaca.

http://zacoeb.lecture.ub.ac.id 